\title{
Benign Eyelid Neoplasm
}

National Cancer Institute

\section{Source}

National Cancer Institute. Benign Eyelid Neoplasm. NCI Thesaurus. Code C4354.

A non-metastasizing neoplasm that arises from the upper or lower eyelid. 